\title{
Prognosis of adolescent partial syndromes of eating disorder
}

\author{
George C. Patton, Carolyn Coffey, John B. Carlin, Lena Sanci and Susan Sawyer
}

\section{Background}

Partial syndromes of eating disorder are common in adolescents but the health significance of these syndromes remains uncertain.

\section{Aims}

To document the health and social adjustment in young adulthood of females assessed as having a partial syndrome of eating disorder in adolescence.

\section{Method}

A community sample of 1943 participants was tracked over 10 years in an eight-wave cohort study. A partial syndrome was defined as the fulfilment of at least two DSM-IV criteria for either anorexia or bulimia nervosa at one assessment or more between the ages of 15 years and 17 years.

\section{Results}

Partial syndromes were found in $9.4 \%$ of 15 - to 17 -year-old female participants and $1.4 \%$ of males. There were few instances of progression of partial syndromes to fully fledged anorexia and bulimia nervosa. However, among those with partial syndromes depressive and anxiety symptoms were two to three times higher in young adulthood, substance misuse was common, and a majority of those with a partial syndrome of anorexia nervosa were still underweight in their mid-20s.

\section{Conclusions}

Given the level of subsequent psychopathology and social role impairment, there may be justification for initiating trials of preventive and early clinical intervention strategies for adolescent partial syndromes.

\section{Declaration of interest}

None.
Two decades ago cross-sectional surveys in community settings found a different profile of eating disorders from that described by clinicians in treatment settings. ${ }^{1}$ Fully fledged anorexia and bulimia nervosa appeared to be relatively rare. In contrast, partial syndromes - with some but not all symptoms of the full clinical syndrome - were common in young women. Population-based surveys consistently found point prevalence rates of around $0.5 \%$ for anorexia nervosa and $1 \%$ for bulimia nervosa in female teenagers. In contrast, rates for partial syndromes were around 3 $5 \% .^{2-4}$ Early longitudinal studies considered the possibility that partial syndromes might develop into full syndromes and thereby be a point for early intervention. However, on 12-month followup most partial syndromes appeared to have resolved spontaneously without progression to either full anorexia or bulimia. ${ }^{5}$ Subsequent retrospective studies with a longer time frame found higher lifetime rates of clinical syndromes than were observed in cross-sectional 'snapshots'. Lifetime risks of eating disorders in adult women have been estimated to be around $8 \%$ for bulimia nervosa ${ }^{6}$ and $3 \%$ for anorexia nervosa. ${ }^{7,8}$ Such findings raised the possibility that eating disorders commonly emerge in milder forms in the mid-teenage years with slower progression to more severe disorders. This would be consistent with the often reported lag of some years before clinical presentation. ${ }^{9}$

A question about the progression of adolescent partial syndromes requires prospective study, ideally in a community setting. Prospective studies of eating disorders outside the clinical setting remain rare. The high rates of continued poor social functioning into young adulthood found in patients with anorexia nervosa ${ }^{10}$ have been replicated in the one study in which a community-based sample was used. $^{11}$ Available community studies of bulimia nervosa also suggest high rates of continued symptoms and social dysfunction. ${ }^{12}$ The outcomes for adolescents with a partial syndrome of eating disorder are far less clear. One study has found that symptoms of eating disorder are associated with psychosocial difficulties in adolescence, but that these problems had largely resolved by young adulthood. ${ }^{13}$ Another found modest evidence for adolescent-young adult continuity in eating disorder symptoms and their associated problems. In a three-wave cohort study of 538 young females from their midteens to the age of 24 years, just under a third of those with a teenage disorder had persisting disorder in young adulthood. ${ }^{14}$ Risks of other psychopathological disorders, particularly depression, as well as poor overall psychosocial adjustment, appeared higher in the adolescent eating disorders group. ${ }^{14,15}$ The available studies are, however, limited in a number of respects: in sample size, in numbers of assessment points for disorders that fluctuate in intensity, in the use of retrospective ascertainment of eating disorders or in the definitions used for adolescent eating disorders. ${ }^{13,14,16}$ For these reasons the clinical relevance of partial syndromes of eating disorder in adolescence has remained unclear.

The study reported here adopted a prospective design in a close-to-representative community sample of almost 2000 participants, with multiple adolescent assessment points, to study the outcomes of adolescent partial syndromes in young adulthood. We examined outcomes that included persisting eating disorder, depressive and anxiety symptoms, body mass, sexual and reproductive health, and social role transitions.

\section{Method}

Between August 1992 and March 2003 we conducted an eightwave cohort study of adolescent and young-adult health in the state of Victoria, Australia. Data collection protocols were approved by The Royal Children's Hospital's ethics in human research committee. The cohort was initially defined with a twostage cluster sample in which we selected two classes at random from each of 44 schools drawn from a stratified frame of all schools (government, Catholic and independent) in the state (total number of students 60905 ). School retention rates to year 
9 in the year of sampling were $98 \%$. One class from each school entered the cohort in the latter part of the 9th school year (wave 1), with a second class entering 6 months later, early in the 10th school year (wave 2). Participants were subsequently reviewed at a further four 6-month intervals during their teenage years (waves 3 to 6) with two follow-up waves in young adulthood, at age 2021 years (wave 7) and 24-25 years (wave 8). In waves 1 to 6 , participants self-administered the questionnaire on laptop computers, ${ }^{17}$ with telephone follow-up of those absent from school. The 7th and 8th waves of data collection were undertaken with computer-assisted telephone interviews.

From a total sample of 2032 students, 1943 (96\%) participated at least once during the first six (adolescent) waves. In the 7th wave, 1601 young adults ( $79 \%$ of the initial sample or $82 \%$ of teenage participants) were interviewed between April and December 1998. In the 8th wave, 1520 (75\% of the initial sample, $78 \%$ of teenage participants) were interviewed between April 2002 and June 2003. Response rates are shown in Fig. 1. Reasons for noncompletion at follow-up were refusal (wave $7, n=152$; wave 8 , $n=269$ ), loss of contact (wave 7, $n=192$; wave $8, n=152$ ) and death (wave $7, n=2$; wave $8, n=7$ ). The mean ages at waves 1,7 and 8 were 14.5 years $($ s.d. $=0.5), 20.7$ years $($ s.d. $=0.5)$ and 24.1 years (s.d.=0.6) respectively.

\section{Measures}

\section{Weight and height}

Weight was measured to the nearest $0.1 \mathrm{~kg}$, with participants wearing minimal school uniform and a further $1 \mathrm{~kg}$ deducted to account for this clothing. Height was taken with shoes removed using a stadiometer and measured to the nearest centimetre. Self-reported weights were used for those who had left school. At waves 7 and 8, weight and height were assessed using self-report, after prior notification that these two questions would be asked at interview.

\section{Eating disorder}

The Branched Eating Disorders Test (BET) was used to assess DSM-IV criteria for eating disorder. ${ }^{18}$ This test was designed for use in teenaged community samples and covers symptoms of eating disorder over the previous 4 weeks. Partial syndromes of eating disorder were based on the DSM-IV criteria for bulimia nervosa and anorexia nervosa, this being the approach most commonly adopted in the definition of these syndromes. ${ }^{19} \mathrm{~A}$ partial syndrome of anorexia nervosa was defined as meeting two of the following four criteria:

(a) low body weight, defined on the basis of a $z$ score for body mass index (BMI) below the 5th percentile for age and gender, using the reference data from the international taskforce for the standardisation of overweight and obesity in children and adolescents; ${ }^{20}$

(b) intense fear of gaining weight or becoming fat when under the 25th percentile $z$ score for BMI for age and gender;

(c) disturbance in the experience of body weight, size and shape when under the 25th percentile $z$ score for BMI for age and gender;

(d) amenorrhoea, defined as missing three consecutive menstrual periods.

A partial syndrome of bulimia nervosa was defined as meeting at least two of the following criteria:

(a) objective bingeing at least weekly for at least 4 weeks;

(b) use of any of the following for at least 4 weeks: self-induced vomiting at least twice weekly, laxatives at least twice weekly, diuretics at least twice weekly, daily fasting ( $12 \mathrm{~h}$ or longer) for at least 4 weeks or daily vigorous exercise to control weight;

(c) report of body weight and shape as extremely important to the participant's sense of self.

Definitions of partial syndrome of bulimia nervosa using the BET have previously been shown high agreement with the Eating Disorders Examination in community sample of schoolgirls in Australia (sensitivity 1.0 , specificity 0.99 , positive predictive value $0.7) .^{21}$ The BET was administered from wave 2 through to wave 6 . At follow-up in wave 7 the BET was administered to female participants only. Therefore this report examines continuity of eating disorder in young females only.

\section{Depression and anxiety}

Symptoms of depression and anxiety were assessed from waves 1 to 7 using the Revised Clinical Interview Schedule (CIS-R). ${ }^{22}$ The total scores on this measure were dichotomised at a cut-off point of $11 / 12$ to delineate a mixed depression-anxiety state at a lower threshold than syndromes of major depression and anxiety disorder but where clinical intervention would still be appropriate. ${ }^{23,24}$ Specific anxiety and depressive syndromes were also defined using the CIS-R. ${ }^{22}$ The 12-item General Health Questionnaire $(\mathrm{GHQ})^{25}$ was used to assess these symptoms at wave 8 : a cut-off score of $2 / 3$ was used to define a group with high psychiatric morbidity.

\section{Substance use (wave 8)}

Nicotine dependence was assessed with the Fagerstrom Test for Nicotine Dependence and was defined as a score of 4 or more. ${ }^{26}$

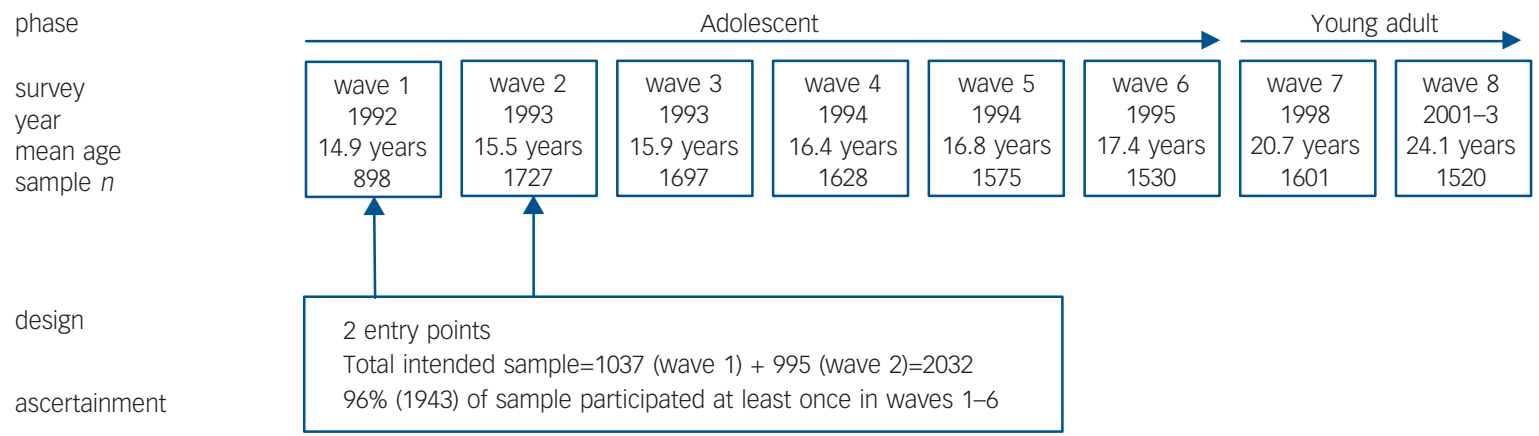

Fig. 1 Sampling and ascertainment in the Victorian Adolescent Health Cohort, 1992-2003. 
Table 1 Cumulative prevalence of partial-syndromal eating disorders in 1943 participants in the Victorian Adolescent Health Cohort Study for waves 3 to 6

\begin{tabular}{|c|c|c|c|c|c|c|c|}
\hline \multirow[b]{3}{*}{ Eating disorder } & \multirow[b]{3}{*}{$n^{\mathrm{a}}$} & \multicolumn{6}{|c|}{ Cumulative prevalence of adolesent eating disorders } \\
\hline & & \multicolumn{2}{|c|}{ Males $(n=943)$} & \multicolumn{2}{|c|}{ Females $(n=1000)$} & \multicolumn{2}{|c|}{ Total $(n=1943)$} \\
\hline & & $\%$ & $(95 \% \mathrm{Cl})$ & $\%$ & $(95 \% \mathrm{Cl})$ & $\%$ & $(95 \% \mathrm{Cl})$ \\
\hline Bulimic disorder & 72 & 1.0 & $(0.3-1.6)$ & 6.4 & $(4.8-8.0)$ & 3.7 & $(2.8-4.6)$ \\
\hline Anorexic disorder & 42 & 0.4 & $(0.0-0.8)$ & 3.8 & $(2.5-5.1)$ & 2.2 & $(1.4-3.0)$ \\
\hline Any eating disorder ${ }^{b}$ & 107 & 1.4 & $(0.6-2.1)$ & 9.4 & $(7.3-11.4)$ & 5.5 & $(4.3-6.7)$ \\
\hline
\end{tabular}

Alcohol misuse and dependence was assessed using the Composite International Diagnostic Interview 2.1, 12-month version (CIDI) to define DSM-IV categories. ${ }^{27}$ Cannabis use was assessed on the basis of self-reported frequency of use over the past year, with high use defined as reported use at least weekly. Amphetamine use was defined as self-reported use in the previous 12 months.

\section{Analysis}

Data collection was undertaken at a developmental point when young people are difficult to trace because of high mobility. Although the initial response was high and attrition low, 36\% of respondents missed at least one wave of data collection in the adolescent phase (waves 1 to 6), leading to a potential bias in summary measures of exposure to cannabis and mental health problems calculated from these data. For example, when we examined characteristics of wave 7 non-completers using logistic regression models, male participants were overrepresented $(\mathrm{OR}=1.9,95 \% \mathrm{CI} 1.5-2.4)$, as were those with a background of parental divorce or separation $(\mathrm{OR}=1.8,95 \%$ CI 1.4-2.5) and those who were daily smokers at study inception $(\mathrm{OR}=2.1,95 \%$ CI 1.5-2.9). To address this selection bias, we used the method of multiple imputation, ${ }^{28}$ with five complete data-sets created by imputation under a multivariate normal model that incorporated all the outcome variables of interest measured at all waves of data collection, along with the fixed covariates of gender, age, rural/ urban residence and parental education (available for all participants). ${ }^{29}$ Participants were classified according to whether they fell into categories of interest at least once during waves 1 to 6 (adolescence) and, separately, in waves 7 and 8 (young adulthood). Data analysis was undertaken using Stata version 8 for Windows. Univariate logistic regression analyses were used

\begin{tabular}{|c|c|c|c|c|c|c|c|c|c|c|c|}
\hline \multirow{2}{*}{\multicolumn{2}{|c|}{$\begin{array}{l}\text { Outcome measured in young } \\
\text { adult waves (waves } 7 \text { and 8) }\end{array}$}} & \multicolumn{10}{|c|}{ Partial syndromal eating disorder diagnosis across waves 3 to 6} \\
\hline & & \multirow{2}{*}{\multicolumn{2}{|c|}{$\begin{array}{l}\begin{array}{l}\text { No eating disorder } \\
(n=905)^{\mathrm{a}}\end{array} \\
\text { Prevalence }\end{array}$}} & \multirow{2}{*}{\multicolumn{2}{|c|}{$\begin{array}{l}\begin{array}{c}\text { Bulimic disorder } \\
(n=64)^{\mathrm{a}}\end{array} \\
\text { Prevalence }\end{array}$}} & \multirow{2}{*}{\multicolumn{2}{|c|}{$\begin{array}{l}\text { Anorexic disorder } \\
\qquad(n=38)^{\mathrm{a}} \\
\text { Prevalence }\end{array}$}} & \multicolumn{4}{|c|}{$\begin{array}{l}\text { Any eating disorder } \\
\qquad(n=94)^{\mathrm{a}}\end{array}$} \\
\hline & \multirow[b]{2}{*}{$n^{\mathrm{a}}$} & & & & & & & \multicolumn{2}{|c|}{ Prevalence } & \multicolumn{2}{|c|}{ Association } \\
\hline & & $\%$ & $(95 \% \mathrm{Cl})$ & $\%$ & $(95 \% \mathrm{Cl})$ & $\%$ & $(95 \% \mathrm{Cl})$ & $\%$ & $(95 \% \mathrm{Cl})$ & OR & $(95 \% \mathrm{Cl})$ \\
\hline \multicolumn{12}{|c|}{$\begin{array}{l}\text { Wave } 7 \text { (average age } 20 \text { years) } \\
\quad \text { Partial syndromal eating disorders }\end{array}$} \\
\hline Anorexic & 17 & 1 & $(0.4-2)$ & 7 & $(0.0-13)$ & 10 & $(0.0-22)$ & 7 & $(1-12)$ & 6.0 & $(1.9-19)$ \\
\hline Bulimic & 22 & 1 & $(0.2-3)$ & 11 & $(2-19)$ & 14 & $(0.8-26)$ & 10 & $(3-18)$ & 8.3 & $(1.9-36)$ \\
\hline Any eating disorder & 37 & 3 & $(1-4)$ & 14 & $(4-25)$ & 21 & $(2-40)$ & 15 & $(5-25)$ & 6.7 & $(2.0-22)$ \\
\hline \multicolumn{12}{|l|}{ Psychiatric morbidity } \\
\hline Depressive syndrome & 129 & 11 & $(9-14)$ & 29 & $(17-41)$ & 32 & $(12-51)$ & 28 & $(17-38)$ & 3.0 & $(1.7-5.2)$ \\
\hline Anxiety syndrome & 33 & 2 & $(1-3)$ & 11 & $(2-20)$ & 16 & $(0.0-37)$ & 12 & $(2-21)$ & 5.2 & $(1.9-14)$ \\
\hline Psychiatric morbidity & 219 & 20 & $(17-22)$ & 47 & $(33-61)$ & 47 & $(29-65)$ & 44 & $(34-55)$ & 3.3 & $(2.1-5.2)$ \\
\hline \multicolumn{12}{|c|}{ Wave 8 (average age 24 years) } \\
\hline \multicolumn{12}{|l|}{ Body mass } \\
\hline Mean BMI & - & 23 & $(23-24)$ & 23 & $(22-25)$ & 20 & $(19-21)$ & 22 & $(21-23)$ & - & \\
\hline Underweight & 246 & 23 & $(20-26)$ & 27 & $(15-40)$ & 65 & $(47-84)$ & 38 & $(27-49)$ & 2.1 & $(1.3-3.3)$ \\
\hline Overweight & 267 & 28 & $(25-31)$ & 23 & $(12-34)$ & 7 & $(0.0-16)$ & 18 & $(10-26)$ & 0.58 & (0.33-1.0) \\
\hline \multicolumn{12}{|l|}{ Substance misuse } \\
\hline Nicotine dependence & 83 & 8 & $(6-10)$ & 17 & $(7-27)$ & 9 & $(0.0-26)$ & 14 & $(5-24)$ & 2.0 & $(0.88-4.5)$ \\
\hline Alcohol dependence & 87 & 8 & $(6-10)$ & 18 & $(5-31)$ & 14 & $(0.0-26)$ & 16 & $(7-25)$ & 2.2 & $(1.0-4.6)$ \\
\hline Alcohol diagnosis & 123 & 12 & $(9-14)$ & 22 & $(9-35)$ & 17 & $(4-30)$ & 19 & $(10-28)$ & 1.8 & $(1.0-3.4)$ \\
\hline Cannabis use $e^{b}$ & 74 & 7 & $(5-9)$ & 12 & $(3-20)$ & 7 & $(0.0-23)$ & 10 & $(2-17)$ & 1.3 & $(0.50-3.6)$ \\
\hline Amphetamine use & 86 & 8 & $(6-10)$ & 23 & $(12-34)$ & 11 & $(0.0-24)$ & 17 & $(8-26)$ & 2.5 & $(1.2-5.0)$ \\
\hline \multicolumn{12}{|l|}{ Psychiatric morbidity } \\
\hline $\mathrm{GHQ}>2$ & 263 & 25 & $(22-28)$ & 40 & $(28-53)$ & 39 & $(23-56)$ & 40 & $(29-50)$ & 2.0 & $(1.2-3.1)$ \\
\hline $\begin{array}{l}\text { BMI, body mass index; GHQ, Gene } \\
\text { One female had died by wave } 8 \text { a } \\
\text { a. Frequencies obtained by avera } \\
\text { b. Weekly use or more. }\end{array}$ & $\begin{array}{l}\text { I Health } \\
\text { so was } \\
\text { g acros }\end{array}$ & $\begin{array}{l}\text { uestionn } \\
\text { xcluded } \\
\text { ive impu }\end{array}$ & $\begin{array}{l}\text { the analysis. } \\
\text { ata-sets. }\end{array}$ & & & & & & & & \\
\hline
\end{tabular}




\begin{tabular}{|c|c|c|c|c|c|c|c|c|c|c|c|}
\hline \multirow{4}{*}{$\begin{array}{l}\text { Outcome measured in young } \\
\text { adult waves (waves } 7 \text { and 8) }\end{array}$} & \multirow[b]{4}{*}{$n^{\mathrm{a}}$} & \multicolumn{10}{|c|}{ Partial syndromal eating disorder diagnosis across waves 3 to 6} \\
\hline & & \multirow{2}{*}{\multicolumn{2}{|c|}{$\begin{array}{c}\text { No eating disorder } \\
(n=905)^{\mathrm{a}}\end{array}$}} & \multirow{2}{*}{\multicolumn{2}{|c|}{$\begin{array}{c}\begin{array}{c}\text { Bulimic disorder } \\
(n=64)^{\mathrm{a}}\end{array} \\
\text { Prevalence }\end{array}$}} & \multirow{2}{*}{\multicolumn{2}{|c|}{$\begin{array}{c}\begin{array}{c}\text { Anorexic disorder } \\
(n=38)^{\mathrm{a}}\end{array} \\
\text { Prevalence }\end{array}$}} & \multicolumn{4}{|c|}{$\begin{array}{l}\text { Any eating disorder } \\
\qquad(n=94)^{\mathrm{a}}\end{array}$} \\
\hline & & & & & & & & \multicolumn{2}{|c|}{ Prevalence } & \multicolumn{2}{|c|}{ Association } \\
\hline & & $\%$ & $(95 \% \mathrm{Cl})$ & $\%$ & $(95 \% \mathrm{Cl})$ & $\%$ & $(95 \% \mathrm{Cl})$ & $\%$ & $(95 \% \mathrm{Cl})$ & OR & $(95 \% \mathrm{Cl})$ \\
\hline \multicolumn{12}{|l|}{ Early sexual activity } \\
\hline Sexually active $<16$ years & 190 & 17 & $(14-20)$ & 35 & (17-53) & 33 & $(21-45)$ & 34 & (24-44) & 2.5 & $(1.5-3.9)$ \\
\hline Sexually active by year 12 & 402 & 39 & $(35-42)$ & 60 & $(39-81)$ & 56 & $(44-69)$ & 57 & $(45-69)$ & 2.1 & $(1.3-3.5)$ \\
\hline \multicolumn{12}{|l|}{ Pregnancies } \\
\hline Live birth & 108 & 10 & $(8.1-12)$ & 13 & $(8-33)$ & 17 & $(4-30)$ & 15 & $(5-26)$ & 1.6 & $(0.66-3.7)$ \\
\hline Termination of pregnancy & 114 & 11 & $(9-13)$ & 15 & $(2-29)$ & 19 & $(7-31)$ & 18 & $(9-26)$ & 1.8 & $(0.91-3.5)$ \\
\hline Miscarriage & 45 & 4 & $(2-6)$ & 10 & $(0.0-23)$ & 10 & $(0.0-22)$ & 9 & $(1-17)$ & 2.4 & $(0.73-7.7)$ \\
\hline Any pregnancy & 222 & 21 & $(18-24)$ & 27 & $(5-48)$ & 34 & $(14-54)$ & 31 & $(18-44)$ & 1.7 & $(0.86-3.3)$ \\
\hline \multicolumn{12}{|l|}{ Relationships } \\
\hline In a relationship & 700 & 70 & $(67-73)$ & 70 & $(42-99)$ & 73 & $(59-87)$ & 70 & $(58-83)$ & 1.0 & $(0.55-1.9)$ \\
\hline Living with a partner & 356 & 35 & $(32-39)$ & 36 & $(15-56)$ & 43 & $(27-60)$ & 37 & $(23-51)$ & 1.1 & $(0.54-2.1)$ \\
\hline \multicolumn{12}{|l|}{ Education } \\
\hline Left school before year 12 & 140 & 13 & $(11-15)$ & 26 & $(8-44)$ & 24 & $(12-35)$ & 25 & $(15-35)$ & 2.2 & $(1.2-4.1)$ \\
\hline Currently studying & 216 & 22 & $(19-25)$ & 13 & $(0.0-25)$ & 19 & $(8-31)$ & 17 & $(8-26)$ & 0.71 & $(0.36-1.4)$ \\
\hline Degree obtained & 464 & 38 & $(45-52)$ & 31 & $(15-47)$ & 28 & $(16-39)$ & 29 & $(19-38)$ & 0.43 & $(0.27-0.69)$ \\
\hline No qualification \& not studying & 234 & 22 & $(19-25)$ & 33 & $(15-51)$ & 36 & $(24-48)$ & 34 & $(23-45)$ & 1.8 & $(1.1-2.9)$ \\
\hline
\end{tabular}

to model associations, and Wald tests and related confidence intervals were used to assess statistical significance and precision.

\section{Results}

Table 1 shows the estimated prevalence for partial and full syndromes of eating disorder between the ages of 15 years and 17 years (waves 3 to 6). Just under one in ten of the female participants fulfilled criteria for an eating disorder over this time. One participant fulfilled all criteria for anorexia nervosa during this time, and four fulfilled all criteria for bulimia nervosa. Eight participants fulfilled criteria for partial syndromes of anorexia and bulimia at different waves. The prevalence rate for partial syndromes in male participants was low, at just over $1 \%$. The OR of an eating disorder was 7.9 (95\% CI 4.1-15) times greater for female participants than for males.

Health outcomes for partial syndromes in young adulthood are shown in Table 2. Results are presented for outcomes at wave 7 (average age 20 years) and wave 8 (average age 24 years). Eating disorders at a partial syndrome level were found in $14 \%$ of those who had an adolescent bulimic partial syndrome and $21 \%$ of those who had had an anorexic partial syndrome. The majority of young-adult cases from the adolescent bulimic group were also bulimic in form. In contrast, new partial syndromes were uncommon in young women without a teenage years diagnosis. Fortyfour per cent of those with an adolescent partial syndrome reported significant psychiatric morbidity at age 20 years, compared with rates of $20 \%$ in other cohort participants $(\mathrm{OR}=3.3$, 95\% CI 2.1-5.2). A similar pattern was evident at the age of 24 years where $40 \%$ of those who had had an adolescent partial syndrome reported high levels of morbidity on the GHQ compared with $25 \%$ of those with no adolescent syndrome (OR=2.0, 95\% CI 1.2-3.1).

The proportion of those underweight in their mid-20s (wave 8) was higher in those with an adolescent partial syndrome (OR=2.1, 95\% CI 1.3-3.3). This was principally because around two-thirds of those with an anorexic partial syndrome remained underweight $(\mathrm{OR}=6.3,95 \% \mathrm{CI} 2.7-14)$. Conversely, those with an adolescent partial syndrome were less likely to be overweight, largely because of the very low rates of overweight in those who had had an adolescent anorexia syndrome (OR=0.18, 95\% CI 0.04-0.82).

Substance misuse was generally higher in the group who had had a partial syndrome during the teens, particularly in the bulimic subgroup. Nicotine dependence was higher in the partial syndrome group at the age of 20 years ( $\mathrm{OR}=2.3,95 \%$ CI 1.0-5.3) and at age 24 years $(\mathrm{OR}=2.2,95 \% \mathrm{CI}$ 0.88-4.6). Alcohol dependence was over twice as common in the partial syndrome group $(\mathrm{OR}=2.2,95 \% \mathrm{CI} 1.0-4.9)$, as was amphetamine use $(\mathrm{OR}=2.5$, 95\% CI 1.2-5.0). In contrast, rates of cannabis use were similar in the two groups.

Table 3 reports social and sexual health outcomes in the mid20 s of those with an adolescent partial syndrome. Females with a partial syndrome were more sexually active before the age of 16 years $(\mathrm{OR}=2.5,95 \% \mathrm{CI} 1.5-3.9)$ and before leaving school $(\mathrm{OR}=2.1,95 \% \mathrm{CI} 1.3-3.5)$. There was a tendency for this group to be more likely to have had a pregnancy and to have had both terminations and spontaneous abortions. Females with partial syndrome were more likely to have left school before year 12 $(\mathrm{OR}=2.2,95 \% \mathrm{CI} 1.2-4.1)$, were less likely to have attained a degree by their mid-20s (OR=0.43, 95\% CI $0.27-0.69)$ and were more likely to find themselves neither working nor studying $(\mathrm{OR}=1.8,95 \%$ CI 1.1-2.9).

\section{Discussion}

This study confirms that partial syndromes are common during adolescence. Around one in ten young females fulfilled criteria for these conditions at some time between the ages of 15 and 17 years. Around one in six of those with an adolescent eating disorder had a persisting partial syndrome as a young adult, consistent with an earlier report from the USA that a majority of such disorders do not persist into young adulthood. ${ }^{30}$ There was little to suggest that partial syndromes progress to clinical eating disorders in the medium term. Nevertheless, female participants with 
a partial syndrome had a broad range of ongoing health and social problems as young adults. Depressive and anxiety syndromes were two to three times more common in this group. Weight disturbance persisted in those with adolescent anorexia partial syndromes, with over two-thirds remaining underweight in their mid-20s. Substance misuse was generally higher, with over twofold higher rates of nicotine dependence, alcohol use disorders and amphetamine use. The psychosexual profile of the partial syndrome group also differed, with high rates of early initiation of sexual intercourse and a tendency towards more early pregnancies. Those with adolescent eating disorder were less likely to have successfully completed their education and to have made a successful transition into employment or vocational training by their mid-20s.

Early studies of the outcomes of partial syndromes focused on clinical samples from which generalisation may be difficult, had limited follow-up or used uncertain measures of the symptoms of eating disorders. ${ }^{31,32}$ The term 'partial syndrome' defines syndromes that are likely to be similar to the DSM-IV category of 'eating disorder not otherwise specified'. A close-to-representative community sample, high participation rates and frequent measures of symptoms during the teenage years are strengths of this study. The use of multiple imputation should have minimised possible biases arising from missing data. It nevertheless remains possible that patterns of association among those who were non-responders might not be fully captured by the imputation modelling, leading to some residual bias in the final estimates. One further limitation is the availability of only one point of assessment for eating disorders in young adulthood. Given that eating disorders may continue to fluctuate in intensity, it is possible that we have underestimated the degree of continuity from adolescence to young adulthood. The ongoing low weight of those who had had an anorexia syndrome is noteworthy in this respect. It would be consistent with continuing body image sensitivity and efforts to control weight even if the individual does not fulfil formal criteria for an eating disorder.

A majority of later health and adjustment problems in young females with an adolescent partial syndrome were not specifically related to ongoing eating disorder. Some of these problems might arise because of the presence of other psychiatric syndromes that commonly co-occur with eating disorders. ${ }^{33}$ Other problems such as educational failure might be the result of disruption to school attendance during the teenage years, a process to which the symptoms of eating disorder may contribute. It is also possible that adolescent partial syndromes are best viewed as a marker for an ongoing susceptibility to a range of psychiatric and behavioural disorders, rather than being linked specifically to anorexia and bulimia nervosa.

Later substance misuse was prominent in the partial syndrome group, suggesting that risk of substance misuse is not limited to those with fully fledged syndromes. ${ }^{34}$ Earlier reports have noted that a range of substances are commonly used by adolescents and young adults with weight concerns and dieting. ${ }^{35,36}$ In our study an association with tobacco and amphetamine use, but not with cannabis use, was prominent. This perhaps reflects an ongoing preoccupation with weight control, with tobacco and amphetamines being recruited for their effects on appetite and weight control. In contrast, cannabis intoxication often brings an increase in appetite that may be a disincentive for use.

A range of difficulties in social adjustment in young adulthood found in fully fledged eating disorders were also evident in those with partial syndromes. ${ }^{15,37}$ The pattern of psychosexual development differed somewhat from that found in fully fledged eating disorders, in which sexual milestones are typically delayed. ${ }^{38}$ It is, however, consistent with the finding of larger population-based surveys, in which bulimic symptoms have been linked to early menarche and in turn to earlier sexual activity. ${ }^{39}$ It is also possible that the impulsivity associated with bulimic syndromes has a role in early sexual activity and the trend towards higher rates of pregnancy. However, these factors cannot account for the apparently high rate of spontaneous first-trimester abortion. Earlier reports have found that active bulimia nervosa during pregnancy is associated with higher rates of miscarriage and that these differences were not accounted for by intercurrent substance misuse. ${ }^{40}$ Our findings raise the possibility that lower levels of eating disorder symptoms might also predict poor pregnancy outcomes.

Few partial syndromes appear to progress to clinical eating disorders in community settings. As a means of preventing full clinical syndromes of anorexia and bulimia nervosa, there appears little justification for early screening and intervention. However, partial syndromes are common and are linked to a range of later health and social problems. From this alternative perspective there is justification for giving clinical attention to this group. Yet clinical response is not likely to be easy. Although screening tools exist for use in community settings, those with probable eating disorder will often not accept referral for treatment. ${ }^{41}$ Eating disorders are not often routinely identified by general practitioners, and given their high prevalence these disorders present a major challenge for existing services. ${ }^{42}$ Treatment may well require the kind of multifaceted psychological approach advocated for the full syndromes of anorexia and bulimia nervosa. ${ }^{43}$ This may be one reason why those presenting for specific treatment of eating disorders in primary care are unlikely to persist with treatment if the clinical intervention is not sufficiently intense. ${ }^{44}$ However, several strategies of response seem worth considering. For particular subgroups such as young females who are pregnant or those with diabetes mellitus, screening and clinical interventions are more likely to meet with success. ${ }^{45,46}$ In primary care a greater attention to general psychosocial risk screening may be more effective in engaging this group than specific screening for eating disorders. ${ }^{47}$ For those identified as having a partial syndrome, there may be greater value in attending to symptoms of depression and anxiety, substance misuse and sexual health problems, as well as the social and educational difficulties so commonly associated with having a partial syndrome. Self-help interventions in non-clinical settings, tied to the promotion of health literacy around eating disorders, might also reduce the substantial disease burden associated with the most common eating disorders of adolescence. ${ }^{48,49}$ A recent finding that internet delivery of cognitive-behavioural therapy brought substantial reductions in symptoms and adverse consequences of common eating disorders for up to 2 years illustrates the potential of this approach. $^{50}$

George C. Patton, MD, MBBS, Carolyn Coffey, BSC, Centre for Adolescent Health Murdoch Children's Research Institute, Parkville, Victoria; John B. Carlin, PhD, Clinical Epidemiology and Biostatistics Unit, Murdoch Children's Research Institute, and Department of Paediatrics, University of Melbourne, Victoria; Lena Sanci, PhD, Department of General Practice, University of Melbourne, Victoria; Susan Sawyer MD, MBBS, Centre for Adolescent Health, Murdoch Children's Research Institute, $\mathrm{MD}, \mathrm{MBBS}$, Centre for Ado
Parkville, Victoria, Australia

Correspondence: Professor George C. Patton, William Buckland House, 2 Gatehouse Street, Parkville, Victoria 3052, Australia. Email: george.patton@ rch.org.au

First received 17 Sep 2006, final revision 19 Aug 2007, accepted 24 Sep 2007

\section{Acknowledgements}

This research was supported by funding from the National Health and Medical Research Council, the Victorian Health Promotion Foundation, and the Victorian Centre for Excellence in Eating Disorders. 


\section{References}

1 Mann AH, Wakeling A, Wood K. Screening for abnormal eating attitudes and psychiatric morbidity in an unselected population of 15-year-old schoolgirls. Psychol Med 1983; 13: 573-80.

2 Johnson-Sabine E, Wood K, Patton G, Mann A, Wakeling A. Abnormal eating attitudes in London schoolgirls - a prospective epidemiological study: factors associated with abnormal response on screening questionnaires. Psychol Med 1988; 18: 615-22.

3 Steinhausen $\mathrm{HC}$, Winkler $\mathrm{C}$, Meier M. Eating disorders in adolescence in a Swiss epidemiological study. Int J Eat Disord 1997; 22: 147-51.

4 Rastam MV, Gillberg C, Garton M. Anorexia nervosa in a Swedish urban region: a population-based study. Br J Psychiatry 1989; 155: 642-6.

5 Patton GC, Johnson-Sabine E, Wood K, Mann AH, Wakeling A. Abnormal eating attitudes in London schoolgirls - a prospective epidemiological study: outcome at twelve month follow-up. Psychol Med 1990; 20: 383-94.

6 Kendler KS, Maclean C, Neale M, Kessler R, Heath A, Eaves L. The genetic epidemiology of bulimia nervosa. Am J Psychiatry 1991; 148: 1627-37.

7 Walters EE, Kendler KS. Anorexia nervosa and anorexic-like syndromes in a population-based female twin sample. Am J Psychiatry 1995; 152: 64-71.

8 Steinhausen $\mathrm{HC}$, Winkler MC, Meier M. Eating disorders in adolescence in a Swiss epidemiological study. Int J Eat Disord 2002; 27: 147-51.

9 Fairburn CG, Welch SL, Doll HA, Davies BA, O'Connor ME. Risk factors for bulimia nervosa: a community-based case control study. Arch Gen Psychiatry 1997; 54: 509-17.

10 Steinhausen HC, Boyadjieva S, Grigoroiu-Serbanescu M, Seidel R, Winkler MC. A transcultural outcome study of adolescent eating disorders. Acta Psychiat Scand 2000; 101: 60-6.

11 Rastam M, Gillberg C, Gillberg IC. A six-year follow-up study of anorexia nervosa subjects with teenage onset. J Youth Adolesc 1996; 25: 439-53.

12 Fairburn CG, Cooper Z, Doll HA, Norman P, O'Connor M. The natural course of bulimia nervosa and binge eating disorder in young women. Arch Gen Psychiatry 2000; 57: 659-65.

13 Steinhausen HC, Gavez S, Winkler MC. Psychosocial correlates, outcome, and stability of abnormal adolescent eating behavior in community samples of young people. Int J Eat Disord 2005; 37: 119-26.

14 Lewinsohn P, Striegal-Moore RH, Seeley J. Epidemiology and natural course of eating disorders in young women from adolescence to young adulthood. J Am Acad Child Adolesc Psychiatry 2002; 41: 1284-92.

15 Striegel-Moore RH, Seeley JR, Lewinsohn PM. Psychosocial adjustment in young adulthood of women who experienced an eating disorder during adolescence. J Am Acad Child Adolesc Psychiatry 2003; 42: 587-93.

16 Kotler LA, Cohen P, Davies M, Pine DS, Walsh BT. Longitudinal relationships between childhood, adolescent and adult eating disorders. J Am Acad Child Adolesc Psychiatry 2001; 40: 1434-40.

17 Paperny DM, Aono JY, Lehman RM. Computer assisted detection and intervention in adolescent high-risk health behaviour. J Pediatr 1990; 116: 456-62.

18 American Psychiatric Association. Diagnostic and Statistical Manual of Mental Disorders (4th edn) (DSM-IV). APA, 1994.

19 Graber JA, Brooks-Gunn J. Co-occurring eating and depressive problems: an 8-year study of adolescent girls. Int J Eat Disord 2001; 30: 37-47.

20 Cole TJ, Bellizzi MC, Flegal KM, Dietz WH. Establishing a standard definition for childhood overweight and obesity worldwide. BMJ 2000; 320: 1240-3.

21 Selzer R, Hamill C, Bowes G, Patton G. The Branched Eating Disorders Test: validity in a non-clinical population. Int J Eat Disord 1996; 20: 57-64.

22 Mann AH, Wakeling A, Wood K, Monck E, Dibbs R, Szmukler G. Screening for abnormal eating attitudes and psychiatric morbidity in an unselected population of 15-year-old schoolgirls. Psychol Med 1983; 13: 573-80.

23 Harrington R, Fudge $\mathrm{H}$, Rutter $\mathrm{M}$, Pickles $\mathrm{A}$, Hill J. Adult outcomes of childhood and adolescent depression: II. Links with antisocial disorders. J Am Acad Child Adolesc Psychiatry 1991; 30: 434-9.

24 Lewis G, Pelosi AJ, Araya R, Dunn G. Measuring psychiatric disorder in the community: a standardized assessment for use by lay interviewers. Psycho Med 1992; 22: 465-86.

25 Goldberg D. General Health Questionnaire (GHQ-12). nferNelson, 1992.
26 Fagerstrom KO, Heatherton TF, Kozlowski LT. Nicotine addiction and its assessment. Ear Nose Throat J 1991; 69: 763-6.

27 World Health Organization. Composite International Diagnostic Interview, CIDI-Auto 2.1 Administrator's Guide and Reference. WHO, 1997.

28 Rubin DB. Multiple Imputation for Non-Response in Surveys. Wiley, 1987.

29 Schafer JL. Analysis of Incomplete Multivariate Data. Chapman \& Hall, 1997.

30 Lewinsohn PM, Striegel-Moore RH, Seeley JR. Epidemiology and natural course of eating disorders in young women from adolescence to young adulthood. J Am Acad Child Adolesc Psychiatry 2000; 39: 1284-92.

31 Herzog DB, Hopkins JD, Burns CD. A follow-up study of subdiagnostic eating disordered women. Int J Eat Disord 1993; 14: 261-7.

32 Patton GC, Johnson-Sabine E, Wood K, Mann AH, Wakeling A. Abnormal eating attitudes in London schoolgirls: a prospective epidemiological study: outcome at twelve months. Psychol Med 1990; 20: 382-94.

33 Kaye WH, Bulik CM, Thornton L, Barbarich N, Masters K. Co-morbidity of anxiety disorders with anorexia and bulimia nervosa. Am J Psychiatry 2004; 161: 2215-21.

34 Herzog DB, Franko DL, Dorer DJ, Keel PK, Jackson S, Manzo MP. Drug abuse in women with eating disorders. Int J Eat Disord 2006; 39: 364-8.

35 Krahn DD, Kurth CL, Gomberg E, Drewnowski A. Pathological dieting and alcohol use in college women - a continuum of behaviors. Eat Behav 2005; 6: $43-52$.

36 Curran HV, Robjant K. Eating attitudes, weight concerns and beliefs about drug effects in women who use ecstasy. J Psychopharmacol 2006; 20: 42531.

37 Hudson Jl, Hiripi E, Pope HG, Kessler RC. The prevalence and correlates of eating disorders in the National Comorbidity Survey Replication. Biol Psychiatry 2007; 61: 348-58.

38 Schmidt U, Evans K, Tiller J, Treasure J. Puberty, sexual milestones and abuse: how are they related in eating disorder patients? Psychol Med 1995; 25: 413-17.

39 Kaltiala-Heino R, Rimpela M, Rissanen A, Rantanen P. Early puberty and early sexual activity are associated with bulimic-type eating pathology in middle adolescence. J Adolesc Health 2001; 28: 346-52.

40 Morgan JF, Lacey JH, Chung E. Risk of postnatal depression, miscarriage, and preterm birth in bulimia nervosa: retrospective controlled study. Psychosom Med 2006; 68: 487-92.

41 Rees L, Clark-Stone S, Rees L, Clark-Stone S. Can collaboration between education and health professionals improve the identification and referral of young people with eating disorders in schools? A pilot study. J Adolesc 2006; 29: $137-51$.

42 King M. Eating disorders in general practice. BMJ 1987; 17: 249-53.

43 Fairburn CG, Cooper Z, Shafran R. Cognitive behaviour therapy for eating disorders: a 'transdiagnostic' theory and treatment. Behav Res Ther 2003; 41: $509-28$.

44 Walsh BT, Fairburn CG, Mickley D, Sysko R, Parides MK, Walsh BT, Fairburn CG, Mickley D, Sysko R, Parides MK. Treatment of bulimia nervosa in a primary care setting. Am J Psychiatry 2004; 161: 556-61.

45 Newton MS, Chizawsky LL, Newton MS, Chizawsky LLK. Treating vulnerable populations: the case of eating disorders during pregnancy. J Psychosom Obstet Gynaecol 2006; 27: 5-7.

46 Goodwin RD, Hoven CW, spitzer RL, Goodwin RD, Hoven CW, Spitzer RL. Diabetes and eating disorders in primary care. Int J Eat Disord 2003; 33 85-91.

47 Goldenring JM, Rosen DS. Getting into adolescent heads: an essential update. Contemporary Pediatrics 2004; 21: 64.

48 Pratt BM, Woolfenden SR. Interventions for preventing eating disorders in children and adolescents. Cochrane Database of Systematic Reviews, issue 2, CD002891. Update Software, 2002

49 Mond J, Hay P, Rodgers B, Owen C. Self-recognition of disordered eating among women with bulimic-type eating disorders: a community-based study. Int J Eat Disord 2006; 39: 747-53.

50 Taylor $\mathrm{CB}$, Bryson S, Luce $\mathrm{KH}$, Cunning D, Doyle AC, Abascal LB, Rockwell R, Dev $P$, Winzelberg AJ, Wilfley DE. Prevention of eating disorders in at-risk college-age women. Arch Gen Psychiatry 2006; 63: 881-8. 